\title{
Comparison of Life Quality for Men in Monogamy and Polygamy Families
}

\author{
Ghasem Esmaili \\ Student of Master in Guidance and Consulting- Islamic Azad University- Khomeinishahr \\ Branch
}

Najme Sadrpushan

Faculty Member- Islamic Azad University- Khomeinishahr

Yousef Gorji

Faculty member, Assistant Professor, Islamic Azad University- Khomeinishahr

Accepted: October 11, 2012 Published: November 12, 2012

Doi:10.5296/jsr.v3i2.2669 URL: http://dx.doi.org/10.5296/jsr.v3i2.2669

\begin{abstract}
The present research consists of comparing Quality of Life for the men in monogamy and polygamy families at Sistan \& Baluchestan. Its statistical population includes all the married men in families at Sistan \& Baluchestan. And from among the cities in this province, Saravan city was selected randomly. And 50 monogamous men and 50 polygamous men $(2$ wives) were selected with the method of "Snow shot". The research method is causal and comparative and for analyzing data, the method of descriptive statistics (frequency, percent, average, and standard deviation) and inferential were used. The tool for collecting data is BREF questionnaire for Life Quality. And the results of the research indicate that Life Quality for monogamous men is more than polygamous men in 3 sub-scales of psychological health, social health, and environmental health, but there is no significant difference in sub-scale of physical health.
\end{abstract}

Keywords: Monogamous Men, Polygamous Men, Life Quality, Family, Marriage

\section{Introduction and Explaining the Matter}

Many of the social, political, cultural and economic matters and problems are usually in the process of changing. Someday in one form, and another day in another form it is created and accepted. Such that a social matter appears in multiple forms at various societies at a time, it may be accepted in a society and rejected in another society. Polygamy or several wives matter is one of the social and cultural problems that during the history depended on various periods, societies and lands. If we look at the past, we find that polygamy order had 
been accepted in all the societies from ancient times and they acted as a norm for it. At the present also in many of the world countries, particularly African, Asian and Latin America countries, the matter of Polygamy has been accepted as a cultural and social norm. But this matter is regarded as an abnormality in another part of the world mainly in North America and Europe and it is considered in contradiction with Human Rights and women's rights. Principally, monogamy matter arises from modern culture and civilization of the West. At present this culture has somewhat developed to other areas of the world as well and it has been accepted in cultural and family order ( Shojaei, 2007). Following recognition of woman as a human who has right, Islam brought new law for women's marriage as well. Islam limited and conditioned having several wives, limited it to maximum 4 wives, whereas before Islam there was no limitation for selecting wife. One man could marry each number of women whom he wanted and there was no obstacle (Motahari, 2010).

From the other side, Islam conditioned having more than one wife on the fully just behavior of the man with his wives. The conditions for observing justice practically prevented men from having several wives. In practice, few men are found who can observe justice and just between their two wives let alone to 3 and four wives. "and if you fear that you cannot act equitably toward orphans, then marry such women as seem good to you, two and three and four; but if you fear that you will not do justice between them; then( marry)only one, or what your right hands possess; this is more proper, that you may not deviate from the right course( Holly Quran, Surah- Nessae, Verses 3).

We have in statistics that in Egypt which is one of the greatest Islamic countries only $4 \%$ of the families have not been monogamy in 1960 and this statistics is only $1 \%$ in Syria. Now you consider that this statistics in Iran will be less than Egypt and Syria to some degree with rising their awareness level during the recent years, accompanied by increasing economic problems and also its bad social and ethical prestige which exist in the customs of our society. For this reason, the important matter is this that inserting such matters and its continuous fostering in various forms in the films and serials only results in removing its ugliness, considering it insignificant from society viewpoint and misusing of it by some individuals. A matter that perhaps today is not in a critical situation, but with continuing this procedure in the future it will confront families with a serious dilemma (Behbahani,2008). Mono-husband and monogamy is the principle in Islam and woman and man want to reach uniqueness in their matrimonial life naturally and it is evident that the spirit of matrimonial life which is uniqueness and unity is found in one wife better and more complete. Thus this is not the problem that monogamy is better or polygamy, the problem is that due to social requisites, specially partial increasing of women in need of marriage to the men in need of marriage, absolute monogamy has practically been endangered and the best way that has the least problems is this polygamy and we can solve its bad points with Islamic training, but the miseries that bachelor women create for the society in case of non- marriage cannot be solved with training and abundant problems have been created for the society by these women (Tabatabai, 1996). Various researches that have been performed by the researchers indicate this very important matter that family center is regarded as a site of health or disease. 
While in family there is correct training accompanied by supporter and encourager as well as presenter of positive and purposeful patterns and a family has strong affective connections, the probability for creating disorder is reduced and in case that a family is stressful and anxious, probability for creating disease and disorder in increased ( Nejati, 1993).

Family is the smallest, most fundamental and oldest social institution. Whereas it seems that it is in the process of collapsing as a result of the pressures and social troubles. Now is the time that we enliven some past values and establish more stable communications in order to help the family from non-identity, isolation and psychological diseases ( Ganji, 1998). Since family is like a tent dwelling the parents ( both father and mother ) constitute its main columns, now if the couples that are their main columns perform their duties well, then the family enjoys appropriate psychological health and life quality and as a result, when the society is dynamic and effective that all of its elements that are the same holy institution of family are considered, studied and recognized from the whole dimensions, and since in former researches the men's role in family was not evaluated very much and they have only studied the women and children in polygamy families against monogamy families, so the present research intends to compare life quality for the men with one wife and several wives who are the same arisen columns of the tent and have effect of the function of the society.

Do men in polygamy families enjoy lower life quality compared to the men in monogamy families ?

\section{Research Hypothesis}

There is significant difference between life quality in monogamy men and polygamy men.

\section{Theoretical Fundamentals}

In Islam marriage is a divine connection. God made it holy for human beings with describing this connection between humans. After regarding the principle of marriage, the family institution has been considered as a foundation in healthy and dynamic society as well as the axis for procurement of needs and also materialization of social duties that repeatedly by Islam prophet and the leaders succeeding him its formation and continuation has been recommended. Family can be defined as a biological, legal and cultural order, even though the origin and basis for family formation is biological bases and it is created by marriage of man and woman, but this biological need itself affects from the society laws and culture. Its evident manifestation can be observed in the form and various shapes of family in various societies.

From the researches of the sociologists in the subject of family institution and the direction of its change we conclude that at ancient times marriage did not constitute and formed family, but existence of family was not related to marriage and with evolution of 
marriage, it has reached to the present stage of wife and husband. As a result, the individuals' viewpoint cannot be similar. From the viewpoint of Loniz \& Morgan, to the time that no rules existed in the field of selecting wife, the society witnessed mixing of the individuals. It means that everyone could have relationship with another one without any forbiddance or legitimacy. At the beginning of family life, man and woman lived in nature like male and female and then they were existed from natural conditions and finally they reach to each other and live together in the stage of husband and wife stage ( Sarukhani, 2010).

Meluti ( 1981) has written that during the evolution date of human, a gradual transfer from sexual sharing to polygamy and monogamy has existed, whereas Rasidley ( 1993) mentioned that humans have had matrimonial connection in the form of polygamy or monogamy, and upon the statement of Marduk(1949), sexual sharing never existed ( quoted from Kanazawa \& Still,1999).

Monogamy is when one man has matrimonial relation with a woman. This form is dominant tradition of most of the societies, since the laws in many countries do not permit having more than one wife at a time, unless in case of separation (divorce) or death of wife, man can marry another one.

Having to wives is when a man marries two women simultaneously. Many of the countries have laws that have forbidden having to wives and even regard it as a guilt. Nevertheless, this form of marriage particularly exists in Moslem countries and some countries.

Polygamy is when a man has married various women simultaneously and has matrimonial relation with them. This form of Polygamy is very prevalent. Polygamy is executed somehow in many traditional African cultures and some countries that today are south Africa and often in south and center of Africa. Of course it is observed in the present Middle East and Moslem countries, Iran ( less) and particularly Arab society. In Bajan tribe at Kamerun polygamy is a prevalent affair and one man may marry 10 women or even more ( Nikleson, 2006).

Following recognition of woman as a human who has right, Islam brought new law for women's marriage as well. Islam limited and conditioned having several wives, limited it to maximum 4 wives, whereas before Islam there was no limitation for selecting wife. One man could marry each number of women whom he wanted and there was no obstacle (Motahari, 2010).

Life quality and evaluation that the individuals have from their life quality has gained much value during the recent years. Some researchers of Toronto University believe that the rate of enjoy that individuals obtain from their life and the rate of satisfaction that they have from their living is the most important opportunity and their potential possibility for enjoying from a happy life and psychological and physical health ( Nasiri, Hashemi \& Hoseini, 2007). 
Engler, Howman (2002) believe that a set of psychological - social factors affect on the experiences of satisfaction from life. These social factors consist of some environmental factors such as health, social welfare, using life standards, training of public health, home, neighborhood and recreational activities. Also, a part of life quality is related to adjusting environmental factors with the person's skills and abilities. They studied life quality generally in 5 scopes. They studied the parents' life quality in relation with need to affection and love, respect, confidence, conciliation and receiving help from others in bad conditions, obtaining meaning, wealth and having enough money. They have defined public health as subjective and objective, physical, matrimonial, social, emotional health evaluation that creates personal growth and purposeful activity.

Brown (2003) suggested 9 important limits for life quality in an extensive study : family relations, support of others from family, welfare services, job and occupational preparation, spiritual and cultural life, recreation, communications with others, partnership and urbanization activities. In this research, it was concluded that : relation between family members, religious and cultural beliefs, occupation were related to family life quality and also the level of family satisfaction reduced with reduction of others' support from family particularly in cases that a type of disability and existed in family (Engler \& Howman, 2002).

Family is the first social environment that the person locates in it and takes effect from it and this taking effect can be biologically or behaviorally. Biological effect of family may make the person susceptible to diseases such as suppression, cancers or behavioral effect such as polyphagia, lack of movement, addiction and alcoholism through the parents' pattern. Health is right of each person and it is a social purpose and all the governments and rulings are duty bound to provide the individuals' health. Changing the diseases' pattern which caused to decrease the rate of infective diseases and increase longevity, results in increasing attention to the concepts of health and life quality during the past decades ( Khosravi, 2007).

In an environment that number of girls is more than the boys and it is performed with the women's satisfaction and its purpose is increasing population and prevention from adultery, may polygamy doesn't have much psychological effect, but in an environment and society that poverty dominates and it is not possible to observe equal rights between the wives such as our present social conditions, it is an action contradictory to the psychological health, especially when those women are made to live together in a house. In addition that such a family is confronted with the worries and problems, the children that are grown in this environment also are subject to types of neuroses ( Mojahed, 2004).

Removing unique physical and affectionate connection often becomes worse by competition of wives. A look at the literature of demography of samples indicated that envy, tension, force and competition is prevalent among the wives in polygamy families. Although there is many cases of communication conflicts between the wives, its most important case is 
negative feeling between wives. Of course this matter can differ in various cultures (Cook \& Kelly, 2006).

\section{Research Method}

The research method was descriptive, from the type of comparative causal, and society in this research includes all the men in monogamy and polygamy families at Sistan and Baluchestan Province in 2012. The subjects were 100 married men which consists of 50 monogamy and 50 polygamy men (two wives).

Due to greatness of the society volume, using stage cluster random method Saravan was selected among Sistan and Baluchestan cities, and with regard to lack of exact statistics for polygamy families, the " snow shot " Method was used. So at first the men were selected in polygamy families ( two wives) that 2 to 4 years had passed from the date of their marriage, and then based on some characteristics such as having four children and their education level of high school certificate and under it, and also the men monogamy families were selected in this form and were simulated.

\section{Measurement Tools}

Short form of Questionnaire for Quality of Life in World Health Organization that is used in various countries and cultures has 26 questions which evaluate four dimensions for the individuals' Quality of Life that include 1. physical health 2. Psychological health 3. Social relations and 4. Social environment. Each domain respectively has 7, 6, 3 \& 8 questions. This Questionnaire has been translated and assessed for validity in more than 40 countries throughout the world ( Nejat, Montazeri, Holakuei Naini, Mohammad \& Majdzadeh, 2007).

Nejat and colleagues (2007) translated this scale and for assessing its validity 167 individuals were selected randomly from Tehran and based on claim of having chronic disease, dischronic disease, chronic patient, and inchronic patient they were divided into 4 groups generally. In order to assess reliability via re-testing, 185 individuals were selected randomly in order that after 2 weeks with access to at least 70 individuals of them re-test is performed.

Reliability of the questionnaire: In the dimension of internal structure the amounts of Cronbach's alpha have been used in the healthy and patient group and in the dimension of re-test Reliability indices of intra-cluster correlation have been used. For studying validity of the questionnaire in distinguishing of healthy groups, chronic patient, non- chronic patient and removing altered variables, linear regression was used. The results obtained from that was as follows: The reliability rates with the index of intra-cluster correlation index within the domain of physical health $77 \%$, in the field of social relations $75 \%$, and finally in the field of environmental health was equal to $84 \%$. Internal adjust of the 4 domains in 
the healthy group was equal to $73 \%$ and in the patient group was $77 \%$. Reliability for distinction of this questionnaire with difference of healthy and patient individuals has been indicated in various areas which was attested with significance in group coefficient after controlling potential altered factors using linear regression. The obtained results express reliability and validity and acceptability of structural factors in this tool at Iran within patient and healthy groups.

In order to organize and summarize raw marks and describe the sample sizes, descriptive statistics ( frequency, percent, average, standard deviation) and also inferential statistics of $\mathrm{T}$ Test and Variance analysis have been used.

\section{Results}

Table (1) Distribution for frequency of subjects based on marriage status

\begin{tabular}{|l|l|l|}
\hline Marriage status & Frequency & Percent \\
\hline Monogamy man & 50 & 50 \\
\hline Polygamy man & 50 & 50 \\
\hline Total & 100 & 100 \\
\hline
\end{tabular}

Table (1) indicates marriage status of individuals in sample group, based on this information.

Table (2) Distribution for frequency of subjects based on education

\begin{tabular}{|l|l|l|}
\hline Education & Frequency & Percent \\
\hline Illiterate & 20 & 20 \\
\hline Under-High school cert. & 38 & 38 \\
\hline High school certificate & 40 & 40 \\
\hline Unspecified & 2 & 2 \\
\hline Total & 100 & 100 \\
\hline
\end{tabular}

As it observed in Table (2), high school certificate education level ( $40 \%$ ), $38 \%$ under high school certificate and $20 \%$ illiterate.

With regard to the research hypothesis for its test, the statistical tests for the coefficient and $t$ of independent groups as well as MANOVA were used that its description is presented in following:

\section{Research Hypothesis}

There is significant difference between life quality of monogamy men and polygamy men. 
Table (3) Average and standard deviation of the marks for the two groups of monogamy men and polygamy men the scale of life quality

\begin{tabular}{|l|l|l|l|}
\hline Groups & Number & Average & standard deviation \\
\hline Monogamy man & 50 & 98.2 & 8.5 \\
\hline Polygamy man & 50 & 89.1 & 12.5 \\
\hline
\end{tabular}

The information inserted in table ( 3 ) indicate average and standard deviation of the marks for the two groups of men and women in the scale of life quality. On the basis of this average, marks for monogamy men is equal to 98.02 and the average marks for the men under study is 89.1 .

Table (4) The results of independent $\mathrm{T}$ Test for comparing life quality between the two groups of monogamy men and polygamy men

\begin{tabular}{|l|l|l|l|}
\hline Variable & T & Freedom degree & Significance level \\
\hline Quality of Life & 4.14 & 98 & 0.001 \\
\hline
\end{tabular}

Table (4) indicates the results obtained from comparing average marks for the two groups. Based on the observed difference between marks of two groups $(P<0 / 01 \& t=4 / 14)$, statistically, its is significant with the confidence level of higher than $99 \%$ which indicates that life quality in monogamy men is better than the polygamy men. On this basis, the research hypothesis is confirmed.

In order to complete information and determining this point that in what dimensions of life quality this difference is significant, the Test of Manova was used that its results are presented in the following.

Table (5) The general results for Manova

\begin{tabular}{|l|l|l|l|l|}
\hline Statistical indices & Statistical rate & F & Freedom degree & Significance level \\
\hline Pilai Effect & 167 & $4 / 77$ & 4 & $0 / 001$ \\
\hline Lambdai Wilks & 833 & $4 / 77$ & 4 & $0 / 001$ \\
\hline Hotling & 201 & $4 / 77$ & 4 & $0 / 001$ \\
\hline greatest Rey Root & 201 & $4 / 77$ & 4 & $0 / 001$ \\
\hline
\end{tabular}

As it is observed in table (5), in general significant difference exist between the two groups concerning the tested variables. In various statistics ( Pilai Effect, Lambdai Wilks, Hotling and the greatest Rey Root), this difference is significant. 
Table (6) The results for Manova in minor scales of Life Quality

\begin{tabular}{|l|l|l|l|l|l|}
\hline $\begin{array}{l}\text { Statistical indices } \\
\text { Variable }\end{array}$ & $\begin{array}{l}\text { Sum of } \\
\text { squares }\end{array}$ & $\begin{array}{l}\text { Freedom } \\
\text { degree }\end{array}$ & $\begin{array}{l}\text { Average } \\
\text { squares }\end{array}$ & F & $\begin{array}{l}\text { Significance } \\
\text { level }\end{array}$ \\
\hline Physical health & $38 / 44$ & 1 & $38 / 44$ & $3 / 03$ & $0 / 08$ \\
\hline $\begin{array}{l}\text { Psychological } \\
\text { health }\end{array}$ & $184 / 96$ & 1 & $184 / 96$ & $16 / 99$ & $0 / 001$ \\
\hline Social health & $51 / 84$ & 1 & $51 / 84$ & $10 / 82$ & $0 / 001$ \\
\hline $\begin{array}{l}\text { Environmental } \\
\text { health }\end{array}$ & $216 / 09$ & 1 & $216 / 09$ & $10 / 48$ & $0 / 002$ \\
\hline
\end{tabular}

The results for variance between the two groups in minor scales of Life Quality are observed in table (6). With regard to these results in 3 sub- scales of psychological health, social health, and environmental health, the difference between the two groups is significant, but the observed difference between the two groups is not significant statistically in subscale of physical health.

\section{Conclusion}

The results obtained from comparison of the average marks for the 2 groups indicated that the observed difference between the two groups marks is significant statistically with the confidence level of higher than $99 \%$. ( $\quad<0 / 01 \& t=4 / 14)$ which indicates that Life Quality is better in monogamy men compare to polygamy men. On this basis, the first hypothesis of the research is confirmed and the results of MANOVA between the two groups in sub-scales of Life Quality indicated that in 3 sub- scales of psychological health, social health, and environmental health, the difference between the two groups is significant, but the observed difference between the two groups is not significant statistically in sub- scale of physical health table (6).

From researchers' viewpoint, non- attendance of father has various effects on girls and boys. In conditions that father does not attend that in our discussion, father of the family naturally cannot be present seriously and effectively at home due to the problems resulted from re-marriage such as make ends meet and simultaneous supervising of 2 or 3 families, and as a result, non- presence of him has some effects. In such families usually the boys are more inclined to violate social rules and norms. Also non- attendance of father has effect on feeling stability of the girls (Mohebi, 2003).

The result of this research is in agreement with Chalbi research (1988). He has concluded that out of 22 patients from married polygamy group, 10 women and 4 men reported that they have disputes in their matrimonial life. It means $64 \%$ of polygamy married ones had regarded polygamy as stressful. This status had been regarded stressful by women more than men. 


\section{Macrothink}

Considering acceptance of polygamy culture in Baluchestan that recently has been faded compared to previously, we can state that during polygamy due to the expansion of their family and the rate of their population, the space of the family becomes full of noise by children and their disputes, particularly if women live together in one house and in that case competition between the women becomes more to the extent that in some families causes to create physical conflicts between them. And finally these matters reduce Life Quality for polygamy men and endangers their social and environmental health as well. But it seems that due to the reason that they want to pretend in the society that being polygamy has had no negative effect in them, they hide their physical pain, non-motion and agility, nonability in performing works and non- satisfaction from their sleep and their need to medical therapy.

\section{With regard to the obtained findings it is suggested that;}

The government can rise the level of people awareness towards the damages of polygamy.

Regarding marriage it is possible that start from educational levels and train them that what means correct marriage and justice between wives.... and how can they have a successful marriage.

Through mass media " Radio, TV, newspaper,..." we can train the correct concept of polygamy to men and women.

Through family courts we can make people and couples aware of the divorce statistics as a result of polygamy.

With regard to the attestation of polygamy in Iran law it is better to explain polygamy culture for Iranian families and describe that polygamy conditions ( justice) is not executable.

\section{Research Suggestions}

To develop researches in the field of difference for polygamy in various cultures.

To develop researches in the field of comparing men and women in monogamy and polygamy families for various variables including matrimonial satisfaction, life satisfaction...

To develop researches for children in polygamy families in the fields of education progress or regress, interest for continuing educations after their father's marriage and training effect

Research in the field of polygamy effects on infective diseases in men and women. 


\section{Macrothink}

\section{Limitations}

Non-cooperation of polygamy families in Baluchestan culture.

Non- generalization of the results to the societies with various cultures

Limitation in exact determining of statistics and numbers for polygamy families.

\section{Acknowledgments}

We would like to express our thanks to Dr. Arbabisarjou, Azizollah, Ph.D and assistant professor at Zahedan University of Medical sciences for spiritual and technical support and his fair guidance and consulting.

\section{Resources}

-Holy Quran : Nesa Sura, Verses 3 \& 29.

-Behbahani, S. (2008). Polygamy, holiness of family, encountering challenges . Nour Specialized Magazines 201.

-Chaleby,K.(1988).Traditional Arabian marriages \&mental health in a group of outpatient Saudis.ActaPsychiatrica Scandinavica,77,139-142.

-Cook'rebecca'I.\&kelly'lisa'M.(2006).Polygyny and canadas obligational human right law.department of justice Canada.

-Engler,J;Hoveman,J.(2002).statwide Quality of life and service satisfaction stady for children and family.michigan department of community health,p 3-4.

-Ganji, H .(2008). Psychological Health. Tehran : Arasbaran Publications.

-Kanazawa,S.\&Still,M.(1999).why monogamy?social forces.78(1).

-Khosravi, S .(2007). Comprehensive Book for General Health. Tehran : Ministry of Health, Treatment \& Medical Education. Chapter 11, section 1.

-Mohebi,F. (2003). West and the phenomenon of mono parent families. Translated by Hajar Hoseini and Fatemeh Bakhtiari. Women Book, Seasonal paper for Women Cultural Social Council. No.24, Tehran.

-Mojahed, A \& Birashk, B.(2004). Children Behavioral Status and psychological health of the parents in polygamy families. Clinical psychiatry and psychology, 3.9. 
-Mottahari, M.(2010). System of woman right in Islam. Tehran : Ale taha, $1^{\text {st }}$ printing.

-Nasiri, H.\& Hashemi, L \&.Hoseini, M.(2007). Studying Life Quality for Shiraz University Students based on the Life Quality scale of World Health Organization. The third country seminar for the students' psychological health. 365-368.

-Nejat, S.\& Montazeri, A.\& HOlakuei Naeini, K.\& Mohamad K \&. Majdzade S,R. (2007). Standardization of the Questionnaire for Life Quality of World Health Organization. Magazine of Health Faculty and Health Research Institute , 1-4, 12, 4.

-Nejati, H. (1993). Training Role of father in family. Tehran : Farzanegan.

-Nichoson,B.(2006).women who shared husbaod:ploygnyin southem Albanian in the earley20th century newcas tleupon tyne ne2 3de,uk.from http:www.elsevier.com/wps/find/homepage.45.57.

-Sarukhani, B. (2010). An Introduction to Family Sociology. . Tehran : Sorush Publications.

-Shojaei, E. (2007). Purposes of Prophet Marriages. Safir Magazine, 4.

-Street, E.(2004) . Family Consulting : Viewpoint and action in systemic views (translated by Mostafa TAbrizi and Ali Alavi NIa). Tehran : Fararavan Publications.

-Tabatabai, S, M, H. (1996). Almizan Fi Altafsir Alquran. Translated by Bagher Musavi Hamedani, Ghom : Azadi Publications.

-Taghavi, S, M ,R .(2008). Norm- finding for Questionnarie of General Health GHQ on Shiraz University Students . two scientific- research monthly paper Daneshvar Raftar, 28.

-Toghi, H. (2001). Modern Society of Baluchestan. Zahedan : Sedighi Publications. 